\title{
Female Principals in the Israeli Arab Society: Between Social Conventions and Self-fulfillment Career
}

\author{
Husein Saris \\ West University of Timisora, Timisora, Romania
}

\begin{abstract}
In recent years, there is an increase in the number of Arab women reaching principal position. This increase is a result of various reasons, among which stands out the wish of Arab women in Israel to challenge traditional values and improve their social status. This study examines strategies used by them to deal with the pressure and workload associated with the principal's role, and cope with unique social and cultural values of the traditional Arab society regarding gender role division. This study used qualitative method based on personal interviews conducted with 10 Arab female principals from diverse backgrounds. The Arab female principals developed certain strategies enabling them to cope with the difficulties of the role which are mostly work overload and pressure, along with the need to overcome traditional social conventions by adopting modern life pattern of new role division within the family, more balance and support, alongside equal division between work and home, good communication, and right time management. The main conclusion is that female Arab principals must cope with higher load due to fact that they live in a traditional society expecting the women to keep house along with the vast workload of principal's role today.
\end{abstract}

Keywords: principal, school management, education, women, Arab society

This study focuses on the self-fulfillment perception of female principals in the Israeli Arab society and the balance they created between the social and cultural functions allotted to women in Arab society and their managerial career. This paper will examine the principals' perception of their role in the family according to social conventions and expectations, and the ways they organize their activities to combine successfully these two central areas: home and career.

The main issue this paper will present and discuss is the strategies used by Arab female principals to maneuver between their managerial role and the customary gender division of the traditional Arab society in Israel.

According to Smooha (2013), the Israeli Arabs are a separate, ethnic, linguistic, cultural, and national minority which does not assimilate in the Jewish majority, maintains separate institutions and communities, and opposes the regime suspected of disloyalty and discrimination. On the other hand, it undergoes empowerment; it is militant, conducting intensive struggle to change its status.

In recent decades, the social and economical structure of the Arab society in Israel underwent accelerated changes; nowadays, scholars are divided whether it should be defined as a traditional society or a society in transition from traditional to modern (Arar \& Oplatka, 2013). This transition is part of a present global socio-economic transition (there). One of the major changes in this phenomenon is the change in the woman

Corresponding author: Husein Saris, $\mathrm{PhD}$ student at Education Administration, MA in Educational Systems Management, West University of Timisora, Timisora, Romania; research field: educational leadership in the Arab sector in Israel. 
status, reflected in her education and her growing integrating in the labor market. According to Ali and Gordoni (2009) and Arar and Abu-Asbah (2010), Palestinian women perceive education as lever to change and improve their social status. These same scholars claim that the Arab society in Israel still maintains certain traditional aspects that conflict with the modernization processes. Therefore, when you examine the status of the Arab woman, it can be seen that although her status has been recently improved due to the rise in her education level and the improvement in her economical situation, there is still no real change in her life at home, since Arab women are still expected to be first and foremost housekeepers and mothers (Shapira, 2006; Shapira \& Arar, 2015).

In recent years, many studies are concerned in female management in educational systems. Oplatka and Hertz-Lazarowitz (2011) found that the sector the female principal comes from affects her form of educational leadership. Their study reveals that female principals from the Israeli Arab society resemble those of female principals from traditional societies in developing countries who must navigate between their feminine identity and social values which exclude women and define leadership in male terms (Shapira \& Arar, 2015).

Arab women seeking a principal's position want to improve their professional position and advance their career. School principal role was complex in the past, and becomes more so today, since school principals operate in dynamic changing reality and are committed to several diverse tasks, thus, the amount of responsibility may cause mental burden (Oplatka, 2007).

The following chapter will present research studies concerned with the woman status in Israeli Arab society, women leadership, schools managed by women in general and by Arab women in particular, and the complexity and workload of the school principal role today. This chapter will be followed by study structure, findings of the interviews conducted, discussion, and conclusions.

\section{Literature Review}

The Israeli Arab society is a heterogeneous society combined of a number of sub-groups and different religions; thus, the change each sub-group goes through can be different (Khattab \& Ibrahim, 2006). With the establishment of the State of Israel, the Arabs lost their relative majority, while the Jews, who lived as a minority in other countries for millennia, suddenly became a majority (Smooha, 2013). Today, the number of Arabs (including Druze and Cherkessk minorities) is $20.7 \%$ of the State's population (The Central Bureau of Statistics, 2014).

Regardless of the changes that occurred in the life style, education level, and social and cultural aspects of the Arab population in Israel, the essence of the distress of the Palestinian Arabs in Israel did not change (Abu-Asbah, 2007). In addition, according to Rudnitzky (2015), regardless of state declarations of intent to reduce the gaps between Jews and Arabs in Israel, significant social-economic gaps still exist.

Rudnitzky speaks about four major barriers that block realization of the government decisions creating difficulties to implement and execute policy that will advance genuine equality of the Arabic population in Israel: the Jewish nature of the state, the security barrier, the bureaucratic barrier, and the fragmentation within the political system (Rudnitzky, 2015).

\section{Women in the Israeli Arab Society}

The Arabic society undergoes change processes in various life areas, such as the family, economy, social and cultural aspects alongside changes in fertility patterns and ratio, and a revolution in education level and 
women work (Yonai \& Kraus, 2009). One of the areas that had been intensively studied in recent years is the social status of Arab Palestinian women, however, most of these studies' concerns relate to their functioning regarding family, values, religion, and the way they affect the woman status; there are hardly any studies relating the woman status and her relations with the various power centers (Sa'ar, 2011; Arar \& Mustafa, 2009).

In recent years, there is indeed a change in the status of the Arab woman in Israel, mainly due to the legislations concerning women status in Israel; nevertheless, their status is still considerably lower than men status in this society. Even the increase in the number of highly educated women and their work outside the house did not bring about a significant change; and they have to compete on their place within the framework of the patriarchal-traditional Arabic society and culture (Gilat \& Hertz-Lazarowitz, 2009; Ali \& Gordoni, 2009).

This treatment of women is expressed among other things in clear distinction between genders' roles and in reducing of female roles economically and employment wisely. Thus, it can be said that Arab women suffer double discrimination: national discrimination, since they belong to a national minority; and gender discrimination, because they live and are raided in a traditional society (Arar \& Abu-Asbah, 2007; 2010).

\section{Women's Self-fulfillment}

According to Idilowitz (2001), the ideal of self-fulfillment exists in several cultures and its characteristics are both utopian and realistic. Self-fulfillment is presented in every person's experience and it is not a stranger to the purposes of humanity that one of its centers of them is achievement of the best.

The will to fulfill oneself or realize oneself in the employment role is perceived in Western society as legitimate and an important and necessary motivation. Rodgers and Scott (2008) claimed that the professional identity is dynamic affected by the environment and the economical, cultural, and political activeness in it. The professional self is shaped through the dynamics between the self and the professional, social, and cultural environment of the self. Other scholars like Kozaminsky (2008) also suggest that the professional self is always in a process of building and development and it can change according to context and relations with others.

According to this scholar, professional identity includes four components that maintain mutual relations among them: the way the profession is perceived in the society, the way the individual perceives the profession, the way the profession is perceived by a professional, and the way he is perceived by other interested parties and others.

Yonai and Kraus (2009) and others claimed that the feminine movement which had developed in the 60s of the previous century brought the message of self-fulfillment to women, as more and more women began to work outside the house, to learn, train, and develop their own career, with a high ratio of mothers having young children seeking work outside their homes. Regardless of growing number of roles, many women chose the effort on giving up what they considered as self-fulfillment by learning, working, and either making a contribution to the household income or becoming economically independent.

\section{Arab Women and Educational Leadership}

Female managers from the Israeli Arab society have to navigate between their feminine identity and traditional social values that perceive leadership as a masculine role. Scholars who study the issue identify a number of barriers leading to reduced representation of women in role of educational leadership; these studies reveal that although women comprise majority of faculty in most schools, their representation in leadership role is far below ratio. 
Scholars (Shapira \& Arar, 2015; Coleman, 2012; 2005; Lumby \& Azaola, 2014) claimed that women bring to managerial positions new values and additional qualities. These claims refer to women in managerial position worldwide and not to any specific culture or region. The study of Coleman (2005) revealed that the number of female principals in the UK and other counties is gradually growing while in developing countries, due to cultural factors, there is a tendency to appoint males for positions of educational leadership. Angela Smith (2008) examined positions fulfilled by Afro-American women in the USA and listed the barriers blocking their way to advance to principals. The first barrier relates to the need to combine career and family duties, and the second barrier is cultural perception of gender related roles according to which, women lack leadership skills and therefore cannot hold managerial positions. The third barrier relates to the women perception of themselves: their tendency to maintain low self-image and their tendency to possess low self-confidence and doubt their abilities. The fourth barrier relates to mobility: Many women have difficulties to travel far from their residence; also, in many cases, women lack connections that might help them to make progress.

In recent years, the status of Arab women in Israel who adopted basic modern principles had been improved. Acquisition of higher education brought femininity of the teaching profession and with it, a slow penetration of women to managerial positions in education. However, this penetration was not easy, since the Arab society perceives school principal as a power position (Mazawi, 2002). In reality, appointment of a school principal in the Arab society involves internal political factors (Shapira \& Arar, 2015); as in some Arabic towns and villages, there is a Hamula (kinship) priority and school principals are appointed from the Hamula of the local mayor (Arar \& Abu-Asbah, 2013).

Oplatka and Hertz-Lazarowitz (2011) examined the reasons for sub-representation in managerial positions in schools and suggested two explanations: The first and main explanation connects to cultural variables. In cultures where there is sub-representation of women, masculine traits are considered effective while feminine traits are considered as ineffective. Thus, since in such culture, there is a perception that masculine values are the right norms for leadership; women are automatically excluded from managerial roles. The other explanation is that man can be dominant and connected in the school.

In the educational system of the Israeli Arab society, $67 \%$ of the school principals are male and only $33 \%$ are female. According to Blas, Givoli, Heiman, and Ofarim (2012), the data indicate a trend of increase in the percentage of female principals. However, when you examine the various groups within the Israeli Arab society, the picture is not that promising, as in the Bedouin society, male principals comprise $94 \%$ of the school principals, and the Druze society, male principals comprise $84 \%$ of the school principals.

It is believed that these numbers reflect a situation resulting from a number of complex, internal, social, and cultural factors, some of which relate to the women themselves. Nevertheless, there is a significant growing group of women who decided to reach principal's position; therefore, there is a need to examine the characteristics of this group to find out whether they share common trends or directionalities that enable them to reach managerial positions.

\section{The Development of Educational Career Among Arab Women}

Career, as a concept studied in the literature, refers to a desired profession or the arrival of a given person to the head of an organizational pyramid (Oplatka, 2007). It is a flexible dynamic concept affected by various environment related factors, the given organization, and the personal aspect. In any role of their career, people 
experience changes in their needs, and in their professional and organizational stands. According to Oshrat (2005), managerial careers follow diverse tracks, sometimes, they are planned and organized; and sometimes, they portray no order or continuation.

Oplatka (2007) studied principals' careers and concluded that there are principals who reached the position after they already fulfilled a number of various roles in school and became professionally established, while others held responsible managerial position elsewhere, and saw educational management as a challenge and opportunity. Some people seek managerial role to advance and improve their income, and others seek the position for various subjective reasons mostly due to individual motivation.

Newton and Witherspoon (2007) found that women are driven to managerial role by internal motivation; they want to be involved in leading teaching and learning processes.

Arar and Shapira (2011) examined the story of two Arab principals and found that the family's background constitutes significant strengthening factor for the women, and that in traditional society, the parents home has an important role in the development of the women and their attaining managerial position. Their findings also confirmed the previously mentioned barriers confronting Arab women seeking a managerial role, specifically local politics and the fact that they belong to the Arab minority.

The vast changes in the educational reality and the reforms applied in many countries affect the role and perception of school management. The modern principal's role includes two main areas: the manager and the organizational leader. The list of his task includes management, activation and motivation of teachers and pupils, strategy, long-term vision, creating relations with the environment, and requiring possession of diverse traits and skills (Shtauber, 2009).

Stoelinga, Hart, and Schalliol (2008) mapped the four major stress and burden factors in principals' work: the demand for immediate measurable academic achievements; social problems within the school's community; difficulties in "sacking" inadequate teachers; and working with parents who are indifferent towards their children. Kats et al. (2009) viewed the issues that the principal is called to deal with the source of stress that could be overwhelming due to the limited time he/she is required to deal with them. So much so, reports revealed that some of the principals find it difficult to cope with the emotional aspects of their work.

Therefore, when we come to examine women from a minority group who entered school principal, we have to examine barriers and factors affecting their getting the position and their integration in their role and the status that comes with it. The study's findings will reveal that although the Arab society in general and women in particular experience several changes in later decades, women who want to reach managerial position still have to deal with several barriers and difficulties.

\section{Research Methodology}

The aim of this study was to examine the ways Arab women cope with the conflict of homemaking and managerial career. The main research question is:

How do Arab female principals reach self-fulfillment in managerial career and maneuver between their managerial position and the clear gender division of the Israeli Arab society?

The secondary research questions derived from the main research question are:

(1) What are the barriers confronting Arab women who want to realize their potential in managerial positions?

(2) How do they manage to integrate their personal life and their career? 
The method used in this study was qualitative analysis based on narratives. The definition of the concept "narrative" in narrative study is: learning the meanings people attribute to their experiences by an endless process of stories about themselves which illustrate their past and their future aims and objectives. The present study had no desire to present causality between certain variables since it focused on a unique phenomenon of a unique group (Chase, 2005).

Research population: 10 female principals of primary schools and junior high schools in Northern Israel.

The research tool is structured in depth interview enabling the researcher to reveal the participants' rich, diverse, multi-dimensional, and social world.

"In the roots of in-depth interview is the desire to understand the experience of other people and the meaning they attribute to the particular experience” (Shkedi, 2003, p. 69).

Participants had been insured of discretion which was kept by using alias.

The interviews were transcribed, analyzed, and subdivided into sections. Data gathered were classified by categories formed when all the sections were reassembled in order to locate subjects shared by some or all participants.

\section{Research Findings}

The findings are presented according to the following themes:

(1) Trends of change in the status of Arab women;

(2) Motives, barriers, and opportunities for self-fulfillment in managerial role;

(3) Managerial career's load and pressure;

(4) Career-family conflict management strategies and ways to reach solutions.

\section{Trends of Change in the Status of Arab Women}

All the research participants agree to the statement that the Israeli Arab society is in transitory stage; there are significant changes in various aspects of life, including life style patterns and woman status. However, certain traditional values regarding gender social roles are still present, especially regarding leadership and management roles. Following are responses and comments of the participants to questions targeting social perception of women as school principals:

Hasna, a participant in her 7th year as principal says that: The Arab society is very sensitive regarding people fulfilling a role, and more so to women fulfilling a role. Miada also is fully aware of barriers and limitations confronted by women, but unlike Hasna, she is more optimistic regarding the present and future of the Israeli Arab society:

"I believe that our society is changing. With time we became more liberated, we certainly adopt more modern life patterns; it is enough to examine the ways women had developed and improved their status".

Rim believes that regardless of the difficulties, women management is better than men management:

"Despite the inbuilt social limitations and the difficulties involved, the woman has a unique power which places her in significantly higher place then a man principal”.

Rim's approach indicates the importance Arab women attribute to managerial positions.

These quotations point out the change in social perception as well as in women perceptions which now maintain that the ability to manage is more important than the gender of the manager. On the other hand, they believe that the fact that there are female school principals is important because it contributes to the 
improvement of the women in the Arab society. As expressed by Suwaed:

"An Arab woman in managerial position plays an important role in the advancement of the women status in my society".

The participants of this study perceive woman management as "fait accompli"; this is a given fact that the Israeli Arab society has already accepted even though it still compounds difficulties to Arab women interested in such roles, as Rana observes:

"There is no doubt that in recent years there is a positive change towards women managers, the present Arab society tends to 'accept' the fact that women fulfill leading positions and present high qualities".

As one can see, the interviewees perceive their role not in its narrow framework of the job, but in the wider scope of advancing their social status, paving the way to others, and canceling rooted cultural values of their society. A number of principals take their job to wider dimensions than the organizational requirements of leading the teachers and the school community and facilitating teaching and learning processes. For example, Rim views her role as an important social position:

"When you manage to solve a problem and mitigate between people and positions of two conflicting parties, people begin to see you as a social leader".

The society does not only "accept" the fact that women are school principals, the female principals are also asked to provide assistance in various issues:

"Somebody came over and asked me to speak with the head of the achievement boost association; he wanted his daughter to study with them and receive stage".

Thus, the fact that women attained the role of school principal is a significant leap in the development of their career and an opportunity to strengthen their status. In the following section, the researcher will elaborate the motives that enabled Arab women to seek an appointment of school principal.

\section{Motives, Barriers, and Opportunities for Self-fulfillment in the Role of School Principal}

The first motive the researcher encountered in this study was the success as a teacher and educator, and in fulfillment of responsible role in the school; following are some of the relevant remarks:

Suwaed says: “...the successes I experienced as a teacher, educator, coordinator, and leading an academic project, the appreciation I felt had an impact, it motivated me to advance”.

Sundus says: "I believe that a woman can combine between her job of any type and her duties at home as mother, the secret is time organization".

Hasna looks beyond the immediate picture: "To repair the world means to repair the education and make teaching and learning more meaningful. This is a sublime target requiring learning, investment and several wars to change the society and make it better”.

Spa'a says:

I felt that I can. I posses the ability that can make the difference in education, rather than administrative job I can just do it... he who get stuck in the same job does not develop and burns ends his career in failure and I have no wish to finish it in failure.

Rim also thinks about the need for social change:

I believed I have the power to give, to advance and affect social change as a woman who has the ability to fulfill this role. I was disrupted by the reality in the field, the unprofessional work and the wrong perception of the role that impaired all strata and levels. 
Despite the feeling of mission and the desire to change, the road for these women to the managerial role was not easy and paved. Not all the participants recommend others to seek principal's position, because:

This is a difficult and dangerous job, especially in society such as the Arab society whose considerations are irrelevant and its opinions are always negative and I do wrong to the woman and indirectly, to the system too since when you are under pressure you are less focused on your work; you are required to waste energy and resources that you would rather invest in the work in improving the system which requires a lot of endurance and efforts to provide for the needs and weaknesses of the society.

Miyada, the principal of a special education school in private ownership mentioned additional barriers she had encountered:

I had encountered several barriers on my way to this role but I overcame all of them. My in-laws did not want me to be a principal; they approached my husband and insisted that it is enough to be a teacher, being a principal requires several working hours and who will be there to take care of him and the children?

However, the barriers described come together with opportunities that are open to women when they achieve a principal appointment; the female principals believe that their role is to train managerial reserve of empowered women who will lead the Arab society to a better way. Rim for example says:

"Each male or female principal has the responsibility to empower leader and train both male and female teachers for the role of principal”.

Miyada also believes that her role provides an opportunity for both personal growth and group growth of the Arabic woman:

I believe that I really grew and became truly empowered at the personal level. I also believe that I inspire several women who desire to reach the same status I obtained. I am partner to a panel of leading women who wish to change our society and make it better.

Although being a school principal serves some women as a lever to improve personal career and improve women status in the society, and despite the holistic perception of a number of principals, the role of school principal is still difficult and complex. From now onward, the researcher will focus on the role perception from the view point of the female principals and elaborate on the pressure and burden accompanying the role.

\section{Pressure and Burden in Managerial Career}

In recent years, the task of school principal changed due to the changes that occurred in the educational reality and the reforms applied in several countries. The perception of principal's role distinguished between two major areas: the managerial area and the leadership area. The managerial area includes organization and daily operation of the school while the leadership area refers to the content climate and atmosphere of the school; the principal is required to lead the assimilation of values and moral, provide inspiration, design aims and objectives, lead renovations, and mostly, motivate people towards the shared goal (Oplatka, 2012).

The female principals think that to manage and lead a school is the best and the most important role there is. Yes, there is a work overload, but there are also so many expectations! Nagiva states:

"My day work begins at 7:30 in the morning and ends at night when I go to sleep".

Sundus lists several roles a principal should fulfill:

“...leadership, school management, teachers development, communication, responsibility and more. The 
main success is to know how to lead and manage the school by building a leading coalition to bring the central people in the faculty to success".

Teachers' development is one of the most important tasks of the principal, Sundus emphasizes that teachers' development means building a pedagogic-organizational culture characterized by high level expectations. The principal has to maintain good communication with all the relevant factors; however, “...activity should be conducted by unilateral channel 'from the top down', without an active participation of the teachers in decision making and execution”.

Burden or overload in the work of teachers and principals is perceived as one of the main pressure factors. Overload is defined as "a condition in which there are too many demands for the existing resources, and it could be quantitative or qualitative” (Oplatka, 2012).

Rim refers to the load in the principal's work:

I forgot I have a home and commitments to my family, my husband and children... My mother always spoke and clasped her hands, repeating the same sentence: "What good the role will do to you if you lose your husband"? I just listened to her and nodded my head, and I went home with head full of thoughts, doubts and uncertainties... at first I thought so much; I cherished my husband and children, and then I reached a point when I realized that this is the most sensitive important issue and I have to rethink things over.

Mona adds:

There is no doubt that there is an immense load on the principal; we are required to bring together different factors for shared objective; parents, pupils, office council, teachers, other interested parties... you barely manage to adapt to a reform and suddenly there is a new reform. Sometimes I feel that I used all my powers and energies.

Rim mentions an external factor that the council does not function, and as a result, her responsibilities areas increase, and the workload grows. She also emphasizes that the role is overloaded not only due to the reasons mentioned but also due to the personal need to lead, to change, and to succeed, meaning the pressure variable is sometimes personal.

The principals' reports echo reports included in the study of Kats et al. (2009) that examined managers' strategies to cope with the workload. In general, we can conclude that the role of school principal is not limited to time and place; it is a very demanding role requiring personal commitment. One of the main issues this study had focused on was the strategies used by the participant to cope with the workload, diminish the pressure, and find the right balance between the family and their career.

\section{Strategies Used by Participants to Manage the Conflict Between Family and Career}

According to Smith (2008), female managers need practical and emotional help to fulfill the demands of both family and career. They need the support of their family and the spouses to fulfill an extremely important role in the success of their managerial experience. In order to combine the demanding pace of the job and family life, women have to stop believing that female managers are not everything for others.

For example, the participant Rim refers to her family and points out that her family is supportive; they understand her need to develop and accept the fact that her work demands much of her time:

As for my family, they obviously share my experience with all that even if I will not get into details, they know how happy I am with the role, they sort of learn me and develop a way, each one a way of his own: how to do, what to do, and when to do, and I am so pleased about it despite the fact that occasionally the pressure is reflected in my behavior and responses at home. The good thing is that my husband and children realize the pressure I am under; they understand that 
sometimes when I react with impatient in certain periods it is just this particular time at work when I am under a lot of pressure and I will probably regret it. My husband and children had managed to learn me well.

Spa'a describes her expectations from her children and reminds the researcher that the children of a principal should behave accordingly:

I am a mother and my children are proud of me, I am proud of them and my husband is proud in his family. I am a mother but I talk to my children and I tell them how children of a school principal should behave.

She claims that she draws a line between work and home: at home she is mother and at school she is the principal. During the entire interview, she insisted on separating home and her managerial work and emphasized that she does not give up being a mom:

At home, it is different. My behavior on the job is very different from the way I behave at home. At work, I know that I have to make a change so I work on it. If I need to advance, I promote my image at school entirely different, perhaps I am slightly tough at school; at home I am someone else.

Later, she says:

I get a lot of respect in society; significantly so after the successes of the school, the projects, and the resulting pupils' achievements, I obtained a significant status in my community. My role gave me social status but at home I am a mother, I will not give up being a mother. I am not a principal in my home; I am a principal only at school.

Rana presents an interesting view:

A school principal is one role, and a mother is another role, though both roles require management. The house also requires management. Sometimes in integrating both managerial styles: in school I behave more intimately, like a family, and at home I am more managerial and it pays.

These perceptions lead the female principals to the choice of action strategy, and those worth mentioning are: balance between work and home, family support, equal work division between the school and the family home, challenging, good communication with all relevant factors, and wise time management. Suwaed says within these contexts that:

It is very important to advance the woman status in my community; I have to be active in my community and volunteer a lot, and on the other hand, I must look after my family and realize my role at home and in the family.

She points out that she is not afraid of the pressure and the workload:

"When we turn the pressure at work into challenge to complete tasks, it motivates us to carry the good day on".

She reports that she maintains good communication with all the factors involved in her life:

"Good communication and good relations reduce uncertainty and conflicts. I usually share my roles and the performance of my tasks with my husband, and I express my criticism if I have any”.

\section{Hasna says:}

I decided not to hurt my family life, which is very important to me. I reached this decision after several doubts and mental reflections. I needed to separate my work as principal and the being of super authority and my role at home where I am a spouse, a wife and a mother of my four sons. It can be achieved by the right time division and assertiveness. To separate and avoid mixing issues and do other things instead of what needed at home.

Sundus says: 
"The secret is to organize the time and work according to plan. I do not feel a workload".

Rim is among the few principals who points out that at the beginning, the role of the principal takes over her life:

I have to confess that in my immediate family circle, my husband and children cope with my needs and the pressure I am under far better than me. They are to ease things for me; they understand my limitations as school principal and assume more responsibilities at home.

Miyada finds ways to mediate between her worlds: "On weekends, Friday and Saturday, my time belongs to my children"; Mona says:

"I found out that there are times when there is less pressure and I make use of these times with my children and my family”.

These findings emphasize that the study participants insist to continue along the path they planned and carry on in the development of their career. Unlike most Arab women, the study participants of female principals adopted modern behaviors and life styles and hoped to influence other Arab women to follow their example.

To sum up the findings of this study, we can conclude that Arab female principals in Israel see their role within a larger scope than being a mere school principal; they perceive themselves as a personal example for other women, and as leading a comprehensive social change in the Arab society. We also find out that the Israeli Arab society is gradually accepting the change in women's image and function and becomes accustomed to the fact that women fulfill management and executive positions. The findings also reveal that regardless of social conventions, the Arab female principals have no intentions to give up their career, nor their family, and they find ways to balance between the demands of their home and their work.

\section{Discussion and Conclusions}

The aim of this study was to find out how Arab women cope with the conflict of being a good homemaker and career in managerial job. The main research question was: How do Arab female school principals navigate between their role as principals and the traditional gender division placed by the Israeli Arab society?

The research findings indicate that there are several diverse barriers which women who seek managerial role confront, however, in recent years, there is a change in the status of women in Arab society; the Arab women today are far more educated than those of previous generation and many of them refuse to accept the traditional perception that places them humbly at home and leaves the men to do things, run things, provide everything, and make all the decisions.

It is also important to note that the Arab society accepts (perhaps de facto, but...) the women who desire to advance and discover their qualities. These statements reflect the feminist idea that aims to advance women's liberty. The findings of this study support those of several other studies. For example, Arar, Masary-Harzalla, and Haj-Yihye (2013) emphasized that the conservative traditional Arab society had opened in recent years and one of the result of it is the fact that women acquire high education and significant roles allotting them high social status.

The study examined the family life of the participants. It has revealed that the female school principals understand the family needs and are aware of the fact that their role as principals consumes mental and physical resources at the expense of the family. Some of the participants reported disputes that arose with the people from the extended family, or disagreements with members of the husband's family. 
Others pointed out that occasionally they cannot find the time for their children or the family in general. Some participants said that they expect their family to behave as expected from the family of a school principal.

However, all the participants pointed out that the society is more open now and is ready to adopt modern values. They know the difficulties and are fully aware of the barriers confronting Arab women seeking an executive position.

The study support findings of previous studies (Oplatka \& Hertz-Lazarowitz, 2011; Shapira, 2006; Arar \& Shapira, 2011; Khattab \& Ibrahim, 2006), which emphasize culture and social related barriers, and family pressure. Some of the participants pointed out that for women in the Israeli Arab society, to fulfill a managerial position are difficult due to certain negative approach and social pressure. Others said that the main problem is the gender, and the negative attitude of local leaders along with lack of support from the husband family.

However unlike these other studies, this study points out a change that more and more women reach the point where they perceive themselves as equal to men and believe that they have the knowledge, the skills, and the ability to be a school principal. Some of the study participants perceive themselves as model for other women, and they believe that they have to train and develop the next leading generation of educated confident women.

This study also revealed that the Arab women in Israel learned how things work in politics, and how local authorities can be bypassed if needed. The number of women in committees that have to choose or appoint school principal is growing, and most of them support and encourage candidacy of women to the role. Once a woman proved herself and becomes a successful principal, the attitude changes; the community and the family learn to respect her status, her leadership, and her abilities. Once the close circle supports her, the female principal can "spread her wings", knowing that others will follow.

School principals are exposed to various pressure sources, and female principals who have to navigate between their role at work and their roles at home are even more so, especially in traditional societies of conservative orientation (Sandberg, 2013). The research findings support reports in the literature (Arar et al., 2013) that combining work outside the home with home tasks is not a simple challenge. In addition, this study revealed that female school principals expect their children to behave according to the mother's status, so they also invest in the family. Nevertheless, most of the study's participants emphasized that they do their best not to bring work and work related issue to their homes.

This study support Colman's (2012) view that despite the workload, pressures, and other problems, the female principals do not give up their desire to prove their worth, become successful manageresses, and find ways to bridge between the two world, management and family life. They adopted more modern life style, divided tasks at home, and managed to get support and assistance from spouses and children. They learned to organize their time effectively, conducted diary and presented mental strength and the ability to say no. Nevertheless, the role and the social status accompanying it alongside the family can be in times overwhelming, therefore, we have to recognize the fact that not too many women, even highly capable ones, are mentally and physically strong enough to fulfill an executive role and function at home as a homemaker and mother simultaneously. Their mental strength relies on environmental support, particularly the support, assistance, and encouragement of the husbands and the immediate family.

The results of this study portrays various factors interesting in current processes that occur within the Arab society in Israel by sheding light on other aspects of working women life, and the change they brought to the perception of women and their social status in the Arab society. 
The main finding of this study is that Arab female principals believe in their right for personal development and self-fulfillment; they believe in their abilities and perceive themselves equal to men, or even more suitable for the role than men. Therefore, they learned to cope with the challenges by strategies that suit both circumstances and their personality.

This study and others like it contribute to the modernization of social perception of women in the Israeli Arab society, by portraying the change the Israeli Arab society undergoes, and by highlighting the respect and appreciation allotted to successful women in their communities.

This study had certain limitations, and the main one was the similarity in the background variables of the participants. A study that will include Arab women principals from the entire country and the diverse ethnic groups and communities would probably yield a picture of much wider dimensions. In addition, it will be worthwhile to compare daily schedule of female principals to that of male principals to shed light on similarities and differences. It is also recommended to study success stories of Arab female principals in order to empower women and emphasize their qualities.

\section{References}

Abu-Asbah, K. (2007). The Arab education in Israel: Dilemmas of a national minority. Jerusalem: Floersheimer Institute for Policy Studies.

Ali, N., \& Gordoni, G. (2009). Ideology of task and authority division in the Palestinian family in Israel: Gender inequality or trends of equality? In F. Azaiza, K. Abu-Baker, R. Hertz-Lazarowitz, and A. Ghanem (Eds.), Arab women in Israel: Status quo and $a$ view to the future. Tel-Aviv: Ramot Press.

Arar, K., \& Abu-Asbah, K. (2007). Education and employment-An opportunity to change the status of Arab women in Israel. In K. Arar and K. Haj-Yihye (Eds.), Academics and higher education among Arabs in Israel: Issues and dilemmas. Tel-Aviv: Ramot Press.

Arar, K., \& Abu-Asbah, K. (2010). Arab women's entrepreneurship in the triangle region of Israel: Characteristics, needs and difficulties. Social Issues in Israel, 9, 91-123.

Arar, K., \& Abu-Asbah, K. (2013). Hindrance factors in the activities of educational departments of the Arab local municipalities. Iyunim Be-Minhal Ve-Irgun Ha-Hinukh, 33, 131-162.

Arar, K., \& Mustafa, M. (2009). Higher education and employment among Arab women: Barriers and changes. In F. Azaiza, K. Abu-Baker, R. Hertz-Lazarowitz, and A. Ghanem (Eds.), Arab women in Israel: Status quo and a view to the future (pp. 259-284). Tel Aviv: Ramot Press.

Arar, K., \& Oplatka, I. (2013). The mode in which Jewish and Arab teachers perceive the masculinity of the principal: Social and cultural aspect of the principal-teacher relation. Iyunim Be-Hinukh, 7(8), 140-160.

Arar, K., \& Shapira, T. (2011). The growing of Nadra \& Samira, two high school principals in a traditional society. Iyunim Be-Minhal Ve-Irgun Ha-Hinukh, 32, 75-96.

Arar, K., Masary-Harzalla, A., \& Haj-Yihye, K. (2013). They wanted me to hover around their eyes. Palestinian students acquiring high education in Israel and Jordan, temporary or permanent immigration. Iyunim Be-Hinukh, 7(8), 161-185.

Blas, N., Givoli, S., Heiman, P., \& Ofarim, Y. (2012). School principals in the light of the data situation picture and future trends. Jerusalem: Avney Rosha Inst.

Chase, S. E. (2005). Narrative inquiry: Multiple lenses, approaches, voices. In N. K. Denzin and Y. S. Lincoln (Eds.), The Sage handbook of qualitative research (3rd ed.) (pp. 651-679). Thousand Oaks, CA: Sage Publications Ltd.

Coleman, M. (2005). Gender and headship in the twenty-first century. Project report. Retrieved from https://core.ac.uk/ download/pdf/83249.pdf

Coleman, M. (2012). Leadership and diversity. In J. Robertson and H. Timperley (Eds.), Leadership and learning (pp. 172-185). London: Sage.

Gilat, A., \& Hertz-Lazarowitz, R. (2009). Religious and non-religious Muslim women experience of empowerment in the private sphere (marriage/parenthood/family). In F. Azaiza, K. Abu-Baker, R. Hertz-Lazarowitz, and A. Ghanem (Eds.), Arab women in Israel: Status quo and a view to the future (pp. 211-236). Tel Aviv: Ramot Press. 
Idilowitz, I. (2001). On the possibility of realizing self-realization. Achva College, 7, pp. 119-141.

Kats, Y., Fiorko, Y., Lis, R., Dor-Hayim, P., Kone, D., Oppenheimer, B., \& Master-Barak, M. (2009). Male and female principals in Israel, a situation picture following a survey conducted among principals and a serial of interviews. Jerusalem: Avney Rosha Inst.

Khattab, N., \& Ibrahim, J. (2006). Why are there so few Palestinian women in principalship positions? In I. Oplatka and R. Hertz-Lazarowitz (Eds.), Women principals in a multicultural society: New insights into feminist educational leadership (pp. 71-88). Rotterdam, Netherlands: Sense Publishers.

Kozaminsky, L. (2008). Professional identity in teaching. Shvele Mahkar, 15, 15-19.

Lumby, J., \& Azaola, M. C. (2014). Women principals in South Africa: Gender, mothering and leadership. British Educational Research Journal, 40(1), 30-44.

Mazawi, A. E. (2002). The Arab education in Israel: Gender, power, teaching and the school as a social field. In M. Zellermeyer and P. Peri (Eds.), Women teachers in Israel: A feminist perspective (pp. 240-252). Tel-Aviv: Hakibbutz Hameuchad Press.

Newton, R. M., \& Witherspoon, N. (2007). Recruiting teachers, principals and superintendents: A job choice theory perspective. Journal of Scholarship and Practice, 3(4), 37-41.

Oplatka, I. (2007). The foundations of educational management-Leadership and management in educational organization. Haifa: Pardes Publication.

Oplatka, I. (2012). School management: From training to retirement. Haifa: Pardes Publication.

Oplatka, I., \& Hertz-Lazarowitz, R. (2011). Women leadership in educational organizations: The uniqueness of Israel in the international context. Iyunim Be-Minhal Ve-Irgun Ha-Hinukh, 32, 51-73.

Oshrat, Y. (2005). Entering the role, the four Ms. Journal for Advancement of Leadership, Professionalism and Excellence, the Ministry of Education Culture and Sport, the Pedagogic Administration, Jerusalem.

Rodgers, C. R., \& Scott, K. H. (2008). The development of the personal self and professional identity in learning to teach. In M. Cochran-Smith, S. Feiman-Nemser, D. J. McIntyre, and K. E. Demers (Eds.), Handbook of research on teacher education: Enduring questions in changing contexts (3rd ed.). New York: Routledge, Taylor \& Francis Group/Association of Teacher Educators.

Rudnitzky, A. (2015). Arab citizens of Israel early in the twenty-first century. Tel Aviv: Institute for National Security Studies (INSS).

Sa'ar, A. (2011). Palestinian-Israeli women's employment: The mystery of their absence and the way to their integration into the formal labor force. Research Report on the Atida Project for Economic Empowerment. Department of Sociology, Haifa University, Haifa.

Sandberg, S. (2013). Lean in: Women, work, and the will to lead. New York, NY: Random House.

Shapira, T. (2006). Blocking and empowerment in the educational space and the public space: Women in the Arab educational systems in Israel. PhD thesis, Educational Faculty, Haifa University.

Shapira, T., \& Arar, K. (2015). Life stories of Arab female principals in Israel: A social cultural political and professional look. Haifa: Pardes Press.

Shapira, T., Arar, K., \& Azaiza, F. (2012). “They didn’t consider me and no-one even took me into account”: Women school principals in the Arab education system in Israel. Iyun U-Mekhkar Behakhsharat Morim, 13, 312-337.

Shkedi, A. (2003). Words that are trying to touch: Qualitative research-Theory and implementation. Tel-Aviv: Ramot Press.

Shtauber, S. (2009). The most complex role-Ynet. Retrieved from http://www.ynet.co.il/articles/07340

Smith, A. M. (2008). Race and gender in the leadership experiences of three female African American high school principals: A multiple case study. Georgia Southern University. Retrieved from http://digitalcommons.georgiasouthern.edu/cgi/view content.cgi?article $=1310 \&$ context $=$ etd

Smooha, S. (2013). Still playing by the rules: The index of Arab-Jewish relations in Israel 2012. The Israel Democracy Institute and University of Haifa.

Stoelinga, S. R., Hart, H., \& Schalliol, D. (2008). The work of Chicago Public Schools’ principals: Leading in a complex context with high stakes. Research report. Consortium on Chicago School Research (CCSR), Chicago, IL.

The Central Bureau of Statistics. (2014). Retrieved from http://www.cbs.gov.il/

Yonai, Y., \& Kraus, V. (2009). Culture or opportunities structure: Why Palestinian women joining the work market is scares? In F. Azaiza, K. Abu-Baker, R. Hertz-Lazarowitz, and A. Ghanem (Eds.), Arab women in Israel: Status quo and a view to the future (p. 122). Tel Aviv: Ramot Press. 